\title{
RESIDENTES DE ENFERMAGEM E A TERAPIA PELA ARTE
}

\author{
NURSING RESIDENTS AND ART THERAPY
}

\section{RESIDENTES DE ENFERMERÍA Y TERAPIA DE ARTE}

\author{
Bismarck Liandro de Freitas ${ }^{1}$ \\ Rosâne Mello ${ }^{2}$ \\ Lucinda Maria Santiago Souza Santos ${ }^{3}$
}

Como citar este artigo: Freitas BL, Mello R, Santos LMSS. Residentes de Enfermagem e a terapia pela arte. Rev baiana enferm. 2021;35:e44427.

Objetivo: relatar os resultados da terapia pela arte por meio de oficinas expressivas aos enfermeiros residentes. Método: estudo descritivo exploratório, de abordagem qualitativa, com análise temática, que apresenta a experiência sentida e vivenciada por sete profissionais enfermeiros do primeiro ano de residência, que participaram das oficinas expressivas em um hospital de grande porte localizado na cidade do Rio de Janeiro, Brasil. Resultados: surgiram os seguintes temas: o ambiente hospitalar como fator estressante; a arte como mecanismo catártico em meio ao sofrimento emocional; olhando para dentro e encontrando equilíbrio; o uso da arte como instrumento para relaxar, descontrair e adquirir novas experiências; conceito ampliado de saúde e doença. Considerações finais: a arte por meio das oficinas expressivas trouxe impactos positivos aos residentes de Enfermagem. A pesquisa mostra que é possível promover saúde por meio da arte.

Descritores: Enfermagem. Terapia pela Arte. Terapias Complementares. Saúde Mental.

Objective: to report the results of art therapy through expressive workshops to intern nurses. Method: exploratory descriptive study, with a qualitative approach, with thematic analysis, which presents the experience felt and live by seven nursing professionals of the first year of residence, who participated in expressive workshops in a large hospital located in the city of Rio de Janeiro, Brazil. Results: the following themes emerged: the hospital environment as a stressful factor; art as a cathartic mechanism in the midst of emotional suffering; looking inward and finding balance; the use of art as an instrument to relax, relax and acquire new experiences; expanded concept of health and disease. Final considerations: art through expressive workshops brought positive impacts to nursing interns. Research shows that it is possible to promote health through art.

Descriptors: Nursing. Art Therapy. Complementary Therapies. Mental Health.

Objetivo: reportar los resultados de la arteterapia a través de talleres expresivos a enfermeros internes. Método: estudio descriptivo exploratorio, con abordaje cualitativo, con análisis temático, que presenta la experiencia sentida y experimentada por siete profesionales de enfermeria del primer año de residencia, que participaron de talleres expresivos en un gran hospital ubicado en la ciudad de Río de Janeiro, Brasil. Resultados: surgieron los siguientes temas: el ambiente hospitalario como factor estresante; el arte como mecanismo catártico en medio del sufrimiento emocional; mirar hacia adentro y encontrar el equilibrio; el uso del arte como instrumento para relajarse, relajarse $y$ adquirir nuevas experiencias; concepto ampliado de salud y enfermedad. Consideraciones finales: el arte a través de talleres expresivos trajo impactos positivos a los internes de enfermería. Las investigaciones demuestran que es posible promover la salud a través del arte.

Descriptores: Enfermería. Arteterapia. Terapias Complementarias. Salud Mental.

\footnotetext{
Enfermeiro. Universidade Federal do Estado do Rio de Janeiro. Rio de Janeiro, Rio de Janeiro, Brasil. bismarck.liandro@hotmail.com. https://orcid.org/0000-00022302-8300.

Enfermeira. Doutora em Enfermagem Psiquiátrica. Professora Associada I da Universidade Federal do Estado do Rio de Janeiro. Rio de Janeiro, Rio de Janeiro, Brasil. https://orcid.org/0000-000 I-6042-4647.

Enfermeira. Especialista em Arteterapia. Rio de Janeiro, Rio de Janeiro, Brasil. https://orcid.org/0000-0003-4026-75। I.
} 


\section{Introdução}

Falar das práticas integrativas e complementares, bem como dos seus benefícios para o indivíduo, certamente não é algo novo; as discussões e sua origem dentro dos sistemas públicos de saúde vêm de longa data. Ainda na década de 1970, em Alma Ata, na Rússia, ocorreu a Primeira Conferência Internacional de Assistência Primária em Saúde. Após essa conferência, surgiram as primeiras recomendações para a introdução das medicinas tradicionais e das práticas complementares em todo o mundo. No Brasil, o movimento começou a ganhar força após a VIII Conferência Nacional de Saúde, ocorrida em $1986^{(1)}$.

Desde então, as práticas integrativas e complementares em saúde têm ganhado cada vez mais espaço, tanto para os usuários do Sistema Único de Saúde (SUS) quanto para os profissionais da saúde, focando a atenção na tríade corpo-alma-mente $^{(2)}$. Atualmente, no SUS, há 29 práticas integrativas e complementares, fazendo inclusive menção ao uso da arte, das expressões artísticas, para promoção de cuidados. Por meio da arte, é possível produzir um transbordamento da subjetividade, possibilitando experimentações por outras linguagens, como a visual, auditiva e corporal. As atividades que são desenvolvidas nesses espaços valorizam as vivências criativas, imaginativas e expressivas, isto é, literalmente uma valorização dos indivíduos ${ }^{(3)}$.

Vale aqui mencionar que a expressão artística é uma atividade milenar. É considerada uma prática expressiva, artístico-visual, que atua como elemento terapêutico na análise do consciente e do inconsciente, buscando interligar o universo interno e externo do indivíduo por meio da simbologia, promovendo a saúde física e mental. É uma arte livre, conectada a um processo terapêutico, com foco no processo criativo, no fazer, que poderá se desdobrar na análise/investigação da sua simbologia, permitindo usar a arte como recurso terapêutico. Os instrumentos utilizados são a pintura, modelagem, colagem, dança, poesia, fotografia, tecelagem, expressão corporal, teatro, sons, músicas ou a criação de personagens, usando a arte em favor da saúde ${ }^{(4)}$.
Dentre tantos indivíduos que podem ser beneficiados com as maravilhas da arte, está o residente de Enfermagem. A residência, para um enfermeiro recém-formado, é algo muito importante. A graduação fornece toda a base teórica para exercer a profissão, no entanto, existe, ainda, a falta da prática profissional, a experiência profissional, que é tanto cobrada pelos gestores e instituições de saúde. Sendo assim, a residência em Enfermagem tem o objetivo de treinar e especializar esse profissional que acaba de sair da academia.

A realidade é que a especialização em área profissional impõe-se e se difunde em todos os países como uma consequência natural do aprofundamento do saber. Torna-se praticamente impossível proporcionar habilitação completa e adequada somente com a graduação. Assim, é concebida a especialização em serviço, devido à sua reconhecida e fundamental importância para a formação do profissional ${ }^{(5)}$.

O curso de pós-graduação, nos moldes de residência, atende às diretrizes da Lei Federal n. 8.080/90, que regulamenta o SUS. Dentre os seus princípios está a organização de um sistema de formação de recursos humanos, atendendo todos os níveis de ensino, bem como a elaboração de programas de aperfeiçoamento de pessoal ${ }^{(5)}$.

É possível inferir que a residência em Enfermagem é uma excelente oportunidade de treinamento em serviço, e se torna um objeto a ser alcançado por muitos egressos da graduação em Enfermagem. Entretanto, o que na grande maioria das vezes não é levado em consideração, é a extensa carga horária do enfermeiro residente, a cobrança, a frustração que pode surgir entre o idealismo e a realidade, a grande expectativa dos profissionais da instituição quanto a chegada dos novos residentes, as atividades teóricas exigidas pela instituição mantenedora da residência, enfim, fatores diversos que, quando somados, podem gerar no residente momentos e situações estressoras.

A residência insere o recém-formado no contexto do trabalho, fornecendo-lhe a oportunidade 
de obter experiência profissional e o título de especialista na área de sua escolha. No entanto, é preciso considerar que esse profissional, recém-formado, com pouco ou nenhum tempo de atuação profissional, pode ter fatores predisponentes ao desenvolvimento de desgaste físico e emocional, tendo em vista ainda que ele exerce uma profissão voltada para o cuidado/ajuda ao outro e que pode, na grande maioria das vezes, estar em intenso sofrimento ${ }^{(6)}$.

Diante do contexto em que está inserido o enfermeiro residente, infere-se que se faz necessário que ele seja cuidado, pois, em sua prática diária, frequentemente está exposto a situações estressoras, o que pode levá-lo a um adoecimento emocional. Com o objetivo de trazer momentos de descontração, socialização, alegrias, literalmente uma catarse, a tutoria da residência de Enfermagem do hospital em questão implementou a arte como forma de cuidado diante das necessidades dos residentes por um alívio, um respirar, promovendo oficinas terapêuticas ao grupo de residentes, sendo nesse contexto que se insere a presente pesquisa. Diante do exposto, surge o seguinte problema de pesquisa: Como a arte, em suas diversas facetas, pode contribuir para uma melhor qualidade de vida desses profissionais recém-formados?

Dessa forma, o objetivo deste estudo é relatar os resultados da terapia pela arte por meio de oficinas expressivas aos enfermeiros residentes.

\section{Método}

Trata-se de estudo descritivo, exploratório, com abordagem qualitativa, que apresenta a experiência sentida e vivenciada pelos enfermeiros residentes que participaram de oficinas expressivas ao longo do primeiro ano do curso de residência.

O presente estudo foi realizado com os enfermeiros residentes do curso de pós-graduação, em nível de especialização, sob a forma de treinamento em serviço nos moldes de residência. A residência da universidade em questão, com ênfase em clínica médica e cirurgia geral, tem duração de dois anos, com carga horária de $60 \mathrm{~h}$ semanais de trabalho em serviço e atividades teórico-práticas.

O início do treinamento dos participantes deu-se em março de 2019, com término em março de 2021. A unidade de treinamento em serviço onde os dados foram coletados para a elaboração da presente pesquisa localiza-se na cidade do Rio de Janeiro e é um Hospital Federal de grande porte.

Participaram das oficinas expressivas, os residentes do primeiro e segundo ano (R1 - 10 residentes e R2 - 9 residentes). Como critérios de inclusão para a elaboração da presente pesquisa, foram convidados a relatar sua experiência nas oficinas expressivas, somente os residentes do primeiro ano, devidamente matriculados no programa de residência em Enfermagem que atuaram no referido hospital. Como critério de exclusão, estabeleceu-se a ausência do residente no período de coleta de dados por motivo de férias, licença médica, outras licenças, não fazer mais parte do corpo de residentes do programa e os residentes do segundo ano, pelo fato de já estarem em fase final da residência e em um outro momento em relação às expectativas e as vivências quanto à experiência de ser residente em Enfermagem.

As oficinas expressivas do presente estudo foram realizadas no período de março de 2019 a janeiro de 2020, totalizando sete sessões. É digno de nota que todas as oficinas expressivas realizadas durante o período foram conduzidas por uma das preceptoras dos residentes, que é enfermeira e possui especialização em Arteterapia.

Com o objetivo de conhecer e identificar os participantes da pesquisa foi entregue um instrumento de contextualização, na forma de questionário de múltipla escolha, contendo sete perguntas, assim como um questionário de avaliação para a coleta de dados. A identificação do participante foi realizada por meio da letra $\mathrm{R}$ (residente) seguido de espaço, que foi numerado de acordo com a ordem de entrega dos questionários respondidos.

O instrumento utilizado para a coleta de dados foi um questionário com oito questões abertas, que possibilitou a análise da experiência 
de cada residente, enquanto participante das oficinas. Todas as questões foram voltadas a descortinar os sentimentos provocados pelas sessões expressivas.

O questionário de avaliação e o instrumento de contextualização dos participantes, na forma de questionário de múltipla escolha, foram entregues a cada participante, com o prazo de duas semanas para serem devolvidos. Destaca-se que o tempo de preenchimento do questionário foi de cerca de 25 minutos.

Após o recebimento dos questionários respondidos, os dados foram analisados na íntegra, com o objetivo de conhecer as experiências de cada residente quanto à sua participação nas oficinas expressivas.

Os participantes do estudo foram orientados quanto ao propósito, os objetivos e os procedimentos da pesquisa e assinaram o Termo de Consentimento Livre e Esclarecido (TCLE). Foi garantido o direito de se retirarem da pesquisa se assim desejassem. Os participantes tiveram a garantia do anonimato devido a utilização da sigla utilizada (R) para a sua identificação, bem como a proteção da identidade, o respeito à individualidade e à privacidade de todos os envolvidos.

A presente pesquisa possui riscos mínimos, pois as informações coletadas foram sobre experiências pessoais, que poderiam trazer aos participantes lembranças de uma situação constrangedora, remetendo a situações desagradáveis que tenham passado. Caso houvesse algum tipo de impacto, o serviço de psicologia hospitalar seria acionado para atender o participante.

Os benefícios da pesquisa para os participantes foram indiretos, pois poderão contribuir para a saúde mental dos próximos residentes, bem como contribuir para futuras melhorias nas próprias sessões de oficinas expressivas, o que não trouxe necessariamente benefícios diretamente ao residente participante da pesquisa. Os dados coletados para a pesquisa serão guardados por cinco anos, e após esse período, serão descartados.

A presente pesquisa foi encaminhada ao Comitê de Ética em Pesquisa (CEP) da universidade mantenedora da residência, pois a unidade (co) participante não possui Código de Endereçamento Postal (CEP) próprio. Esta pesquisa foi aprovada pelo Comitê de Ética e Pesquisa da Universidade Federal do Estado do Rio de Janeiro, Certificado de Apresentação para Apreciação Ética (CAAE): 34978920.5.0000.5285, e atendeu à Resolução n. 466/2012, do Conselho Nacional de Saúde, que dispõe sobre pesquisas envolvendo seres humanos.

\section{Resultados}

O Quadro 1, a seguir, demonstra os resultados do instrumento de contextualização dos participantes da pesquisa.

Quadro 1 - Instrumento de contextualização dos participantes da pesquisa quanto ao estado civil, faixa etária, sexo, raça/cor, religião, tempo de experiência e motivação

\begin{tabular}{|l|l|l|l|l|l|l|l|}
\hline Residente & $\begin{array}{c}\text { Estado } \\
\text { civil }\end{array}$ & Faixa etária & \multicolumn{1}{|c|}{ Sexo } & $\begin{array}{c}\text { Cor/ } \\
\text { raça }\end{array}$ & \multicolumn{1}{|c|}{ Religião } & $\begin{array}{c}\text { Tempo de } \\
\text { experiência }\end{array}$ & Motivação \\
\hline R 1 & Solteiro & 26 a 30 anos & Feminino & Pardo & Evangélico & 1 a 2 anos & $\begin{array}{l}\text { Adquirir } \\
\text { experiência } \\
\text { e pelo } \\
\text { certificado }\end{array}$ \\
\hline R 2 & Solteiro & 26 a 30 anos & Masculino & Pardo & $\begin{array}{l}\text { Sem } \\
\text { religião }\end{array}$ & Até 1 ano & $\begin{array}{l}\text { Adquirir } \\
\text { experiência } \\
\text { e questões } \\
\text { econômicas }\end{array}$ \\
\hline R 3 & Casado & 31 a 35 anos & Feminino & Branco & Católico & 2 a 3 anos & $\begin{array}{l}\text { Adquirir } \\
\text { experiência, } \\
\text { primeiro } \\
\text { emprego } \\
\text { e pelo } \\
\text { certificado }\end{array}$ \\
\hline
\end{tabular}


Quadro 1 - Instrumento de contextualização dos participantes da pesquisa quanto ao estado civil, faixa etária, sexo, raça/cor, religião, tempo de experiência e motivação

\begin{tabular}{|l|l|l|l|l|l|l|l|}
\hline Residente & $\begin{array}{c}\text { Estado } \\
\text { civil }\end{array}$ & Faixa etária & \multicolumn{1}{|c|}{ Sexo } & $\begin{array}{c}\text { Cor/ } \\
\text { raça }\end{array}$ & \multicolumn{1}{|c|}{ Religião } & $\begin{array}{c}\text { Tempo de } \\
\text { experiência }\end{array}$ & \multicolumn{1}{c|}{ Motivação } \\
\hline R 4 & Solteiro & 25 anos & Feminino & Negro & $\begin{array}{l}\text { Sem } \\
\text { religião }\end{array}$ & Até 1 ano & $\begin{array}{l}\text { Adquirir } \\
\text { experiência } \\
\text { e pelo } \\
\text { certificado }\end{array}$ \\
\hline R 5 & Casado & 25 anos & Feminino & Branco & Evangélico & 1 a 2 anos & $\begin{array}{l}\text { Adquirir } \\
\text { experiência }\end{array}$ \\
\hline R 6 & Casado & 31 a 35 anos & Feminino & Pardo & Católico & $\begin{array}{l}\text { Acima de } 3 \\
\text { anos }\end{array}$ & $\begin{array}{l}\text { Adquirir } \\
\text { experiência }\end{array}$ \\
\hline R 7 & Solteiro & 26 a 30 anos & Feminino & Negro & Católico & Até 1 ano & $\begin{array}{l}\text { Adquirir } \\
\text { experiência } \\
\text { e questões } \\
\text { econômicas }\end{array}$ \\
\hline
\end{tabular}

Fonte: Elaboração própria.

Como mostra o Quadro 1, quatro $(57,14 \%)$ participantes eram solteiros, três $(42,85 \%)$ casados, com idade entre 25 e 35 anos; o sexo da maioria dos partícipes foi o feminino, sendo seis (85\%) do sexo feminino e um (14\%) do sexo masculino; quanto à raça/cor, três $(42,85 \%)$ se autodeclararam pardos, dois $(28,14 \%)$ da raça/cor negra e dois $(28,14 \%)$ brancos; em relação à religião, prevaleceu a católica com três (42,85\%) participantes, seguida da religião evangélica com dois $(28,57 \%)$ e dois $(28,57 \%)$ participantes sem religião; sobre o tempo de formação no período da realização das sessões de oficinas expressivas, o resultado foi excepcionalmente diversificado, sendo três $(42,85 \%)$ com tempo de formação de até um ano, dois (28,57\%) de um a dois anos, um entre dois e três anos (14,28\%), e um (14,28\%) acima de três anos. Quanto ao questionamento sobre o motivo que os levou a escolher fazer residência, ganhou destaque o fator adquirir experiência (100\%), seguido por obter o certificado com três respostas $(42,85 \%)$, questões econômicas dois participantes (28,57\%), e primeiro emprego um (14,28\%) participante.

Um fato que certamente chama a atenção é o gênero dos participantes, pois a enfermagem é tida como uma profissão predominantemente feminina. As mulheres representam cerca de $70 \%$ da força de trabalho total de saúde e assistência social. É digno de nota que o contexto do exercício da enfermagem historicamente está vinculado às qualidades femininas, pois o trabalho da enfermagem foi diretamente ligado ao trabalho da mulher, seguindo um conceito machista e estereotipado sobre a mulher ${ }^{(7-8)}$.

Foi questionado aos participantes se eles aceitaram de livre e espontânea vontade participar das sessões de oficinas expressivas, isto é, se eles tiveram a opção de não participar das sessões, caso não quisessem, e também sobre o número de vezes em que cada um esteve presente nas sessões.

Todos (100\%) os residentes de enfermagem declararam ter aceitado de livre e espontânea vontade participar das sessões de oficinas expressivas, o que se considera um dado relevante, que mostra que os participantes da presente pesquisa mostraram-se favoráveis às práticas integrativas e complementares em saúde. Com relação à quantidade de sessões que cada um participou, quatro $(57,14 \%)$ participaram de todas as sessões, dois $(28,57 \%)$ de cinco sessões e um $(14,28 \%)$ participou de quatro sessões.

Após a leitura de todas as respostas do questionário com perguntas abertas, estas foram transcritas manualmente e relidas. O objetivo era encontrar, extrair códigos que posteriormente se tornariam temas, visto que a proposta deste estudo foi justamente fazer uma análise temática dos dados coletados, seguindo a proposta de Virginia Braun e Victoria Clarke. Em seguida, procedeu-se as etapas iniciais propostas pelas 
autoras, que são: familiarizar-se com os dados; gerar códigos iniciais; buscar temas; revisar os temas; definir e nomear os temas. Foram encontrados cinco temas, demonstrados no Quadro 2, a seguir ${ }^{(9)}$.

Quadro 2 - Análise temática dos dados coletados

\begin{tabular}{|l|l|}
\hline CÓDIGOS & \multicolumn{1}{c|}{ TEMAS } \\
\hline Estresse, rotina, trabalho, alívio & O ambiente hospitalar como fator estressante \\
\hline Externalizar, sofrimento, ansiedade & $\begin{array}{l}\text { A arte como mecanismo catártico em meio ao } \\
\text { sofrimento emocional }\end{array}$ \\
\hline $\begin{array}{l}\text { Autoconhecimento, enriquecedor, paciência, } \\
\text { reflexão, enfrentamento }\end{array}$ & Olhando para dentro e encontrando equilíbrio \\
\hline $\begin{array}{l}\text { Descanso, paz, relaxamento, aprendizado, } \\
\text { novidade, criatividade, curiosidade }\end{array}$ & $\begin{array}{l}\text { O uso da arte como instrumento para relaxar, } \\
\text { descontrair e adquirir novas experiências }\end{array}$ \\
\hline Cuidado, saúde, realidade & Conceito ampliado de saúde e doença \\
\hline
\end{tabular}

Fonte: Elaboração própria.

Temas

$\mathrm{Na}$ busca por temas que transmitissem de forma global exatamente a ideia central ou itens de significação dos elementos inseridos dentro das respostas dos participantes, os dados foram analisados em essência para descobrir os núcleos de sentido presentes na comunicação. Os temas e sua respectiva contextualização são descritos a seguir.

\section{O ambiente hospitalar como fator estressante}

Os enfermeiros residentes, ao responderem o questionário com questões de respostas abertas sobre as suas vivências nas sessões de oficinas expressivas, deixaram emergir a palavra estresse com certa frequência, o que denota de alguma maneira o ambiente hospitalar como um fator, um local de trabalho estressante.

Acho importante, pois ajudou a diminuir o sofrimento psíquico, e ajuda no enfrentamento da dor, diminui o estresse. (R6)

A evidência mais marcante sobre o ambiente hospitalar ser um local estressante, na narrativa dos participantes, foi a resposta de três integrantes na questão que indagou sobre o que os levou a aceitarem participar das sessões de oficinas expressivas.
Por ter períodos de descanso e estar fora dos setores. (R1).

A necessidade de sair um pouco do setor/rotina. Dar uma aliviada no estresse. (R3).

Novas experiências e a oportunidade de renovar o ânimo saindo um pouco do ambiente estressante de trabalbo. (R5).

\section{A arte como mecanismo catártico em meio} ao sofrimento emocional

Alguns participantes relataram que ter participado das sessões de oficinas expressivas trouxe alívio e reflexão sobre os seus sentimentos, auxiliando na expressão do que estavam sentindo.

Acho válida, pois é um tipo de ferramenta que relaxa e auxilia a se expressar melhor. (R7).

Foi enriquecedor, tanto na minha vida pessoal [expressão de sentimentos] como no profissional aumento do vínculo com meus colegas. (R4).

Desestressante. (R3).

Acho interessante no sentido de conbecer o que a pessoa/paciente está sentindo, a fim de que o mesmo externalize e possa tratar. (R1).

Olhando para dentro e encontrando equilíbrio

Percebeu-se certa necessidade entre os integrantes da pesquisa de encontrar um ponto de equilíbrio emocional, até mesmo reencontrar-se consigo mesmo, fazendo um resgate do seu eu interior. 
[...] pude perceber o quanto as práticas integrativas podem nos auxiliar na forma como lidamos com nossos anseios e com os problemas coletivos. (R4).

Muito bom, pois além de relaxar eu conseguia ter um novo olhar sobre mim mesma. (R5).

[...] o beneficio do autoconhecimento e poder parar um instante me desligando de todos os problemas externos. (R5).

Importante, pois muitas pessoas precisam sair da rotina, relaxar, se autoconhecer. (R3).

Relaxamento, autoconhecimento, aliviada no estresse. (R3).

Troca de experiência, trouxe mais expectativa para o futuro. (R6)

\section{O uso da arte como instrumento para} relaxar e descontrair

Foi notória a necessidade dos participantes de ter algo que os fizesse relaxar e descontrair, algo que pudesse fazê-los trazer à memória pensamentos positivos, que renovasse as suas energias.

[...] gosto de estar com os outros residentes em momentos descontraídos. (R1)

Muito enriquecedor, pois através da arte conseguimos nos conectar com nosso interior e ter um novo olbar, uma nova perspectiva sobre nossa realidade, contribuindo com nosso bem-estar psíquico e físico. (R5).

Foi gratificante, por ter um tempo a mais com os nossos amigos, compartilhamos nossas experiências. (R6).

[...] além de ter me sentido mais relaxado. (R2).

Paciência para realizar algumas atividades $e$ desenvolvimento de habilidades que não sabia que conbecia. (R7).

Em uma das questões do instrumento de coleta de dados solicitou-se aos participantes relatar em três palavras seus sentimentos por ter participado das sessões de oficinas expressivas, tendo sido unânime a positividade, como demonstram algumas respostas:

Paz, enriquecedor, relaxante. ( $\mathrm{R} 7)$

Descanso, relaxante, compartilhar. (R1)

Autoconbecimento, relaxar, aprendizado. (R5).

Relaxante, importante, desestressante. (R3).

\section{Conceito ampliado de saúde e doença}

Dois participantes levantaram um tema bastante relevante em relação ao modo de se fazer e promover saúde, sobre o uso da arte como uma terapia dentro da saúde, trazendo o tema conceito ampliado de saúde/doença.

\begin{abstract}
Acho útil e muito eficaz [por experiência própria]. Entretanto ainda é vista por muitos profissionais como algo sem valor e sem comprovação científica. Acredito que a maior parte da assistência é baseada em tecnologia leve-dura. (R4).

O ambiente hospitalar traz situações estressantes e de dificil resolutividade. A Arteterapia em contrapartida promove um momento de reflexão acerca da nossa prática profissional, priorizando um momento de cuidado do residente no que diz respeito à questão mental e psicológica. (R2).
\end{abstract}

\section{Discussão}

Os achados da presente pesquisa corroboram o que outras pesquisas já demonstraram: que o ambiente hospitalar se constitui um ambiente de trabalho verdadeiramente estressante. Evidências mostram que o estresse está presente em diversas profissões, porém os profissionais que lidam com relações interpessoais fazem parte de uma classe de trabalho mais afetada pelo adoecimento gerado pelo estresse. Esses profissionais estão constantemente expostos a eventos estressores, como a sobrecarga de trabalho, alta responsabilidade e constante tomada de decisão. O trabalho em um hospital não ocorre de modo linear, sendo construído a cada dia, tornando-se um fator gerador de ansiedade. O estresse exerce uma influência direta na vida pessoal e profissional de um indivíduo, sendo passível de ocasionar uma ruptura no equilíbrio interno do organismo $^{(10-12)}$.

Foi possível perceber nas respostas de alguns participantes certa necessidade em externalizar os seus sentimentos, um desejo de relaxar, algo que pudessem fazer para expressar, movimentar as suas subjetividades. A arte tem esse poder, e com base na narrativa dos integrantes da pesquisa, pode-se concluir que as oficinas expressivas foram um meio para transcender os momentos ruins, configurando-se em um instrumento de cuidado. A arte permite a expressão das emoções, que levam ao equilíbrio do indivíduo com o meio, promovendo uma reorganização psíquica, isto é, uma ferramenta para o enfrentamento e a resiliência dos participantes da pesquisa ${ }^{(13-14)}$. 
É certo que as produções simbólicas e as expressões dos sentidos, mediadas pelo uso das artes, contribuem para o autoconhecimento do indivíduo, na percepção dos seus padrões de respostas às situações e na consciência de seus limites, escolhas e vida, aspectos que corroboram, em última análise, maior eficácia nas suas relações e integração social e, principalmente, consigo mesmo, capacitando os indivíduos para uma vida com autonomia e independência. Estar em um ambiente hostil, que frequentemente expõe o indivíduo a estímulos estressores, sejam esses estímulos reais ou percebidos, exige alta capacidade para que este se adapte socialmente a esse local. Entretanto, é importante que o sujeito disponha de recursos e estratégias que o ajudem a se habituar à determinada realidade, algo que o apoie na resolução do problema e favoreça equilíbrio nos momentos críticos de tensão ${ }^{(14-17)}$.

Os participantes explicitaram que, por meio da arte, foi possível expressar o desejo de encontrar uma solução para as angústias vivenciadas. A arte permite a significação dos conteúdos inconscientes, que são trazidos à consciência e modificados, criando algo novo e solucionando o conflito, o que pode-se deduzir da explanação dos participantes, como um ponto de equilíbrio atingido. Cabe aqui salientar que a arte permite ultrapassar o pensamento, gerando emoções que o próprio indivíduo não é capaz de definir ou até mesmo explicar. As emoções advindas pela arte não podem ser explicadas por seus elementos isoladamente, mas somente pelo produto que o conjunto da obra produz, pois, mais que o pensamento, a arte envolve exatamente o sentimento. Com a arte é possível tocar nos cinco sentidos de uma pessoa: visão, audição, olfato, tato e paladar. Autores defendem que é possível construir um caminho terapêutico por meio da arte, que permite evoluir nas fragilidades psicológicas ${ }^{(16,18)}$.

Cada vez mais tem sido evidenciado que o envolvimento com a arte pode contribuir para a promoção da saúde, sinalizando caminhos para que a arte e a saúde possam, juntas, gerar bem-estar. A aproximação entre arte, saúde e cultura faz emergir um novo campo de saberes em que a saúde passa a ser relacionada também à possibilidade de experienciar a criatividade, de participar das trocas sociais, de ter, ainda, acesso a experiências culturais. Assim, as manifestações artísticas e culturais passam a ser compreendidas como coadjuvantes na produção da saúde, podendo reorientar os modos de viver, de adoecer e de (se) cuidar ${ }^{(18)}$.

É possível dizer, ainda, que a arte é um grande instrumento de inclusão e de produção de subjetividades. Com as vivências artísticas, os indivíduos percebem que possuem múltiplas possibilidades imaginativas e criadoras, que são livres. Por meio das oficinas expressivas, da arte em si, é possível a criação de novos mundos, outras formas de experimentar o viver, novos caminhos para a vida. Dessa maneira, as oficinas não propõem uma única, mas infinitas possibilidades de experimentar a arte. Um mergulho dentro do caos, no qual se permite uma vivência libertária ${ }^{(3)}$.

Alguns participantes trouxeram em suas respostas o conceito ampliado de saúde. As medicinas tradicionais e complementares são abordagens de cuidado e recursos terapêuticos que se desenvolveram e têm um importante papel dentro da saúde global. A Organização Mundial da Saúde (OMS) incentiva e fortalece a sua inserção, reconhecendo e regulamentando essas práticas, produtos e praticantes nos Sistemas Nacionais de Saúde. O processo de criação do SUS tem contemplado diversas propostas de mudanças no olhar sobre a saúde, com maior ênfase na integralidade da assistência e na produção do cuidado ao indivíduo. Em uma sociedade na qual a saúde é dominada por convênios e medicações, cujo objetivo é gerar cada vez mais lucro e fragmentar o tratamento do paciente em especialidades que nem sempre dão conta da totalidade do ser humano, formas de se produzir saúde olhando o indivíduo como um ser biopsicossocial são tidos como um alívio ${ }^{(1,19-21)}$.

\section{Considerações finais}

Conclui-se que a arte, por meio das oficinas expressivas, trouxe grandes impactos positivos 
na vida dos participantes desta pesquisa. Certamente, foi notória a importância de haver no hospital um instrumento para trazer alívio, momentos de lazer e relaxamento aos enfermeiros do primeiro ano de residência em clínica médica e cirurgia geral da unidade hospitalar em questão.

É certo que a arte foi uma ferramenta utilizada para movimentar a subjetividade de cada participante envolvido. Pode-se deduzir esse fato pela alta adesão dos participantes às práticas integrativas e complementares em saúde do SUS, que têm a integralidade como um de seus princípios. É olhar o sujeito em sua totalidade, pelo amplo aspecto biopsicossocial.

A presente pesquisa deixa claro que é possível trabalhar com as práticas integrativas $\mathrm{e}$ complementares dentro de uma unidade hospitalar de grande porte, abrindo portas para que sejam realizadas outras pesquisas com esta mesma temática nas unidades de saúde terciária, pois é fato que o modelo medicalocêntrico e baseado na polimedicação cada vez mais tem se mostrado ineficiente.

\section{Colaborações:}

1 - concepção, projeto, análise e interpretação dos dados: Bismarck Liandro de Freitas, Rosâne Mello e Lucinda Maria Santiago Souza Santos;

2 - redação do artigo e revisão crítica relevante do conteúdo intelectual: Bismarck Liandro de Freitas e Rosâne Mello;

3 - aprovação final da versão a ser publicada: Bismarck Liandro de Freitas, Rosâne Mello e Lucinda Maria Santiago Souza Santos.

\section{Referências}

1. Telesi Júnior E. Práticas integrativas e complementares em saúde, uma nova eficácia para o SUS. Estud av. 2016:30(86):99-112. DOI: $\quad$ https://doi.org/10.1590/S0103-40142016. 00100007

2. Climaco LCC, Almeida JS, Ferraz IS, Aragão AS, Duarte ACS, Boery RNSO. Conhecendo as práticas integrativas e complementares em saúde: oficina educativa. 2019:13(4):1167-72. Rev Enferm UFPE on line. DOI: https://doi. org/10.5205/1981-8963-v13i04a237410p1167$1172-2018$

3. Pádua FHP, Morais MLS. Oficinas Expressivas: uma inclusão de singularidades. Psicol USP. 2010:2(21):457-78. DOI: http://dx.doi.org/10.1590/ S0103-65642010000200012

4. Brasil. Ministério da Saúde. Práticas Integrativas e Complementares (PICS): quais são e para que servem [Internet]. Brasília (DF); 2019 [cited 2019 Nov 11]. Available from: https://antigo.saude.gov.br/saude-de-a-z/ praticas-integrativas-e-complementares

5. Brasil. Ministério da Saúde. Guia de Orientações para o Enfermeiro Residente [Internet]. Brasília (DF); 2005 [cited 2019 Nov 11]. Available from: https://bvsms.saude.gov.br/bvs/publicacoes/guia_ orientacoes_enfermeiros_residentes.pdf

6. Tavares KFA, Souza NVDO, Silva LD, Kestenberg CCF. Ocorrência da síndrome de Burnout em enfermeiros residentes. Acta Paul Enferm. 2014;3(27):260-5. DOI: https://doi. org/10.1590/1982-0194201400044

7. Gugel SCR, Duarte CS, Lima APL. Valorização da enfermagem brasileira: analisando aspectos históricos e de gênero. Nursing. 2020;23(264): 3930-3. DOI: https://doi.org/10.36489/nursing. 2020v23i264p3930-3937

8. Conselho Federal de Enfermagem. Obstáculos relacionados ao gênero enfraquecem trabalho de enfermeiras [Internet]. Brasília (DF); 2019 [cited 2020 Oct 18]. Available from: http:// www.cofen.gov.br/obstaculos-relacionados-aogenero-fortalecem-potencial-de-enfermeiras-dizpesquisa_71605.html

9. Souza LK. Pesquisa com análise qualitativa de dados: conhecendo a Análise Temática. Arq bras psicol. 2019;71(2):51-67. DOI: http://dx.doi. org/10.36482/1809-5267.arbp2020v72s1p.80-93

10. Silva JM, Malagris LEN. Percepção do estresse e estressores de enfermeiros de um hospital universitário. Estud pesqui psicol [Internet]. 2019 [cited 2020 Oct 13];19(1):71-88. Available from: http://pepsic.bvsalud.org/scielo.php?script $=$ sci_ arttext\&pid=S1808-42812019000100005\&lng=pt\&n $\mathrm{rm}=\mathrm{iso} \& \ln \mathrm{g}=\mathrm{pt}$

11. Vilela GS, Ferraz CMLC, Moreira DA, Caram CS, Brito MJM. Construção identitária do enfermeiro em face do processo de distresse moral em um 
centro de terapia intensiva. REME-Rev Min Enferm. 2020;24:e-1334. DOI: 10.5935/1415.2762.20200071

12. Rodrigues CCFM, Santos VEP. O corpo fala: aspectos físicos e psicológicos do estresse em profissionais de enfermagem. J. res.: fundam care online. 2016;8(1):3587-96. DOI: 10.9789/21755361.2016.v8i1.3587-3596

13. Vale KC, Naves MR, editors. Quando as janelas se abrem: o papel da arte na reabilitação. São Paulo (SP): Núcleo de Comunicação do SUS Campinas; Secretaria Municipal de Saúde Campinas-SP; 2010. Vídeo [cited 2020 Oct 13]. Available from: https://suscampinas. wordpress.com/2010/11/10/video-quando-asjanelas-se-abrem/

14. Roscoche KGC, Sousa AAS, Aguiar ASC. Artes visuais no cuidado de enfermagem em saúde mental: uma revisão integrativa. Arch Health Sci. 2019;26(1):55-61. DOI: 10.17696/23183691.26.1.2019.1271

15. Oliveira KS, Nakano TC. Avaliação da resiliência em Psicologia: revisão do cenário científico brasileiro. Psicol Pesqui. 2017;12(1):73-83. DOI $10.24879 / 2018001200100283$

16. Faria PMF, Dias MSL, Camargo D. Arte e catarse para Vigotski em Psicologia da Arte. Arq bras psicol. 2019;71(3):152-65. DOI: http://dx.doi. org/10.36482/1809-5267.ARBP2019v71i3p.152-165

17. Menegatti MS, Rossaneis M, Schneider P, Silva LGC, Costa RG, Haddad MCL. Estresse e estratégias de coping utilizadas por residentes de enfermagem. REME - Rev Min Enferm. 2020;24: e-1329. DOI: $10.5935 / 1415-2762.20200066$

18. Petersen CB, Lima RAG, Boemer MR, Rocha SMM. Necessidades de saúde e o cuidado de enfermagem. Rev Bras Enferm. 2016:69(6):1168-71. DOI: https://doi.org/10.1590/ 0034-7167-2016-0128

19. Brasil. Ministério da Saúde. Política Nacional de Práticas Integrativas e Complementares no SUS: Atitude de Ampliação de Acesso [Internet]. 2a ed. Brasília (DF); 2015 [cited 2019 Nov 11]. Available from: https://bvsms.saude.gov.br/ bvs/publicacoes/politica_nacional_praticas_ integrativas_complementares_2ed.pdf

20. Silva MEB, Torres QSN, Silva TB, Araújo CS, Alves TL. Práticas Integrativas e Vivências em Arteterapia no Atendimento a Pacientes Oncológicos em Hospital Terciário. Rev Portal [Internet]. 2018 [cited 2020 Nov 13];3(1):721-31. Available from: http://www.seer.ufal.br/index. $\mathrm{php} / \mathrm{nuspfamed/article/view/4458/3720}$

21. Brasil. Ministério da Saúde. Portaria n. 971, de 3 de maio de 2006. Aprova a Política Nacional de Práticas Integrativas e Complementares (PNPIC) no Sistema Único de Saúde [Internet]. Brasília (DF); 2006 [cited 2019 Nov 11]. Available from: https://bvsms.saude.gov.br/bvs/publicacoes/ politica_nacional_praticas_integrativas_ complementares_2ed.pdf

Recebido: 24 de fevereiro de 2021

Aprovado: 24 de julho de 2021

Publicado: 27 de agosto 2021

A Revista Baiana de Enfermagem utiliza a Licença Creative Commons - Atribuição-NãoComercial 4.0 Internacional.

https://creativecommons.org/licenses/by-nc/4.0/

Este artigo é de acesso aberto distribuído sob os termos da Licença Creative Commons (CC BY-NC).

Esta licença permite que outros remixem, adaptem e criem a partir do seu trabalho para fins não comerciais. Embora os novos trabalhos tenham de lhe atribuir o devido crédito e não possam ser usados para fins comerciais, os usuários não têm de licenciar esses trabalhos derivados sob os mesmos termos. 